\title{
NUMERICAL ANALYSIS OF STRESS AND STRAIN IN SPECIMENS WITH RECTANGULAR CROSS-SECTION SUBJECTED TO TORSION AND BENDING WITH TORSION
}

\author{
Sebastian FASZYNKA*, Janusz LEWANDOWSKI*, Dariusz ROZUMEK* \\ *Faculty of Mechanical Engineering, Department of Mechanics and Machine Design, \\ Opole University of Technology, ul. Mikołajczyka 5, 45-271 Opole, Poland \\ sebastian.faszynka@op.pl, janusz210@wp.pl, d.rozumek@po.opole.pl
}

received 4 May 2015, revised 12 December 2015, accepted 22 December 2015

\begin{abstract}
The paper presents an analysis of the state of stress and crack tip opening displacement (strain) in specimens with rectangular cross-section subjected to torsion and combined bending with torsion. The specimens were made of the EN AW-2017A aluminium alloy. The specimens had an external unilateral notch, which was $2 \mathrm{~mm}$ deep and its radius was $22.5 \mathrm{~mm}$. The tests were performed at constant moment amplitude $M_{T}=M_{B T}=15.84 \mathrm{~N} \cdot \mathrm{m}$ and under stress ratio $R=-1$. The exemplary results of numerical computations being obtained by using the FRANC3D software were shown in the form of stress and crack tip opening displacement (CTOD) maps. The paper presents the differences of fatigue cracks growth under torsion and bending with torsion being derived by using the FRANC3D software.
\end{abstract}

Keywords: Numerical Method, Fatigue Crack Growth, Torsion and Bending with Torsion

\section{INTRODUCTION}

Extremely fast development of technology causes that the current numerical methods often replace analytical methods and they reinforce the analysis of experimental research studies. The disadvantages associated with experimental tests are their timeconsumption and costs for performing them. Nowadays, basic numerical methods being commonly used in engineering calculations are the finite element method (FEM) (Zienkiewicz and Taylor, 2000; Kleiber, 1995; Szusta and Seweryn, 2010) and the boundary element method (BEM) (Becker, 1992). Those methods allow achieving fast and relatively accurate solutions to many issues in the design of machines, which would be exceptionally difficult or even impossible when using analytical methods (Rusiński, 2002). Today, many large and medium-sized enterprises could not imagine starting production of a new product, before it undergoes positive verification by using numerical methods. These methods allow for modeling the maps of stress, displacement and strain in accordance with the analytical solution in terms of both, the linear and non-linear range. Moreover, they allow for calculation of many others parameters required by the user, such as: the stress intensity factor, the crack tip opening displacement or the J-integral (Rozumek and Macha, 2006; Döring et al., 2006). Using the numerical methods, it should be kept in mind that it is recommended to compare the obtained results with analytical calculations or experimental research carried out in the field, as far as it is possible. It should be considered that the results of numerical calculations describing the behavior of the complex model will be presented in an approximate manner. Moreover, it should be also note that these results are subject to a certain error. One method for solving such complex models is their transformation into several simplified models. The main purpose of the finite element method is to divide the continuous geometric model into finite elements being combined into the so-called nodes, the result of which is the development of discrete geometric model. Boundary element method employs the fundamental solution (differential equations). Approximation takes place explicity on the edge of the tested area of the body without any interference in the internal area. Finite (boundary) elements are interrelated in nodes, and this ensures the system parameters' continuity (Rozumek and Macha, 2006). The research paper (Derpeński and Seweryn, 2007) presents the results of numerical analysis of stress field and strain under tensile in notch type specimens. The specimens were made of the EN 2024 aluminum alloy. Moreover, the stress criterion of specimens cracks emanating from notched, considering the maximum values of plastic shear strain. The authors of the research paper (Duchaczek and Mańko, 2012) proposed methods for determining value of the stress intensity factor by using the FRANC2D software. The research work (Seweryn, 2002) indicates the accuracy of calculation of the stress intensity factor and the way in which the stress values near the crack tip are being changed.

The aim of the paper is the analysis of the state of stress and the crack tip opening displacement (strain) at the bottom of the notch, as well as presenting the changes in fatigue cracks growth behaviour under torsion and bending with torsion in specimens with rectangular cross-section.

\section{SUBJECT OFSTUDY}

Specimens with rectangular cross-section and gross dimension $8 \times 10 \mathrm{~mm}$ were the subject of numerical computations (Fig. 1). The specimens were made of the EN AW-2017A (PA6) aluminium alloy with mechanical properties shown in Tab. 1.

The specimens had an external unilateral notch, which was $\mathrm{a}_{0}$ $=2 \mathrm{~mm}$ deep and its radius was $\rho=22.5 \mathrm{~mm}$. The theoretical stress concentration factor in the specimen was estimated accord- 
ing to the equation provided in the research work (Thum et al., $1960)$, which under bending was $K_{t}=1.04$.
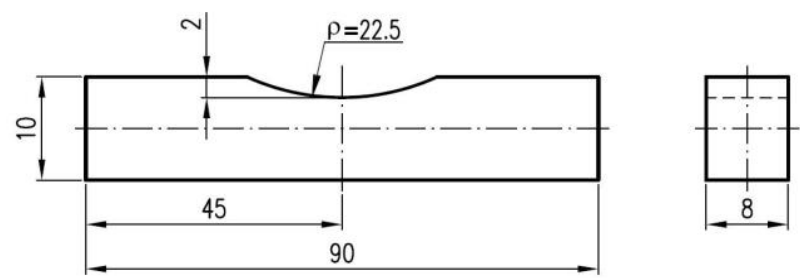

Fig. 1. Shape and dimensions of specimens for fatigue crack growth tests, dimensions in $\mathrm{mm}$

Tab. 1. Mechanical properties of the EN AW-2017A aluminium alloy

\begin{tabular}{|c|c|c|c|}
\hline$\sigma_{y}(\mathrm{MPa})$ & $\sigma_{u}(\mathrm{MPa})$ & $E(\mathrm{GPa})$ & $v(-)$ \\
\hline 382 & 480 & 72 & 0.32 \\
\hline
\end{tabular}

Alloys of aluminium with copper and magnesium -that is duralumin- belong to alloys characterised by supreme strength properties. Chemical composition of the tested EN AW-2017A aluminium alloy shown in Table 2 (Rozumek and Macha, 2009). The longitudinal microsection shown in Fig. 2 indicate structures heavily dominated by elongated grains of the solid solution $\alpha$ of various sizes and at width of approx. $50 \mu \mathrm{m}$. Between large elongated grains clusters of very small equiaxed a phase grains in the system band are visible, as well. On the base of solid solution a, numerous precipitation of intermetallic phases, particularly $\mathrm{Al}_{2} \mathrm{Cu}$, as well as $\mathrm{Mg}_{2} \mathrm{Si}$ and $\mathrm{AlCuMg}$ are seen. Precipitations of the $\mathrm{Al}_{2} \mathrm{Cu}$ phase occur mainly in the chain system on grain boundaries of the solid solution, and their size does not exceed 5 $\mu \mathrm{m}$ (Rozumek et al., 2015).

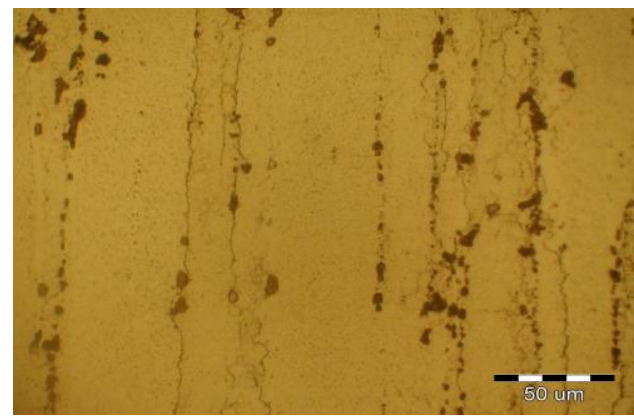

Fig. 2. Microstructure of the EN AW-2017A aluminium alloy, magnification $500 x$

Tab. 2. Chemical composition of the tested EN AW-2017A alloy ( $w t \%)$

\begin{tabular}{|c|c|c|c|c|}
\hline $\mathrm{Cu}-4.15 \%$ & $\mathrm{Mn}-0.65 \%$ & $\mathrm{Zn}-0.50 \%$ & $\mathrm{Mg}-0.69 \%$ & $\mathrm{Fe}-0.70 \%$ \\
\hline $\mathrm{Cr}-0.10 \%$ & $\mathrm{Si}-0.45 \%$ & $\mathrm{Ti}-0.20 \%$ & Al - Balance & \\
\hline
\end{tabular}

Numerical computations were carried out under torsion and proportional bending with torsion. Proportional bending with torsion was obtained through the ratio of torsional and bending moments, which amounted to $M_{T} / M_{B}=\tan \alpha=1$. The computations were performed at constant moment amplitude $M_{T}=M_{B T}=$ $15.84 \mathrm{~N} \cdot \mathrm{m}$. The tests were performed at load frequency $28.4 \mathrm{~Hz}$ and stress ratio $R=-1$.

\section{NUMERICAL COMPUTATIONS OF STATE OF STRESS AND CRACK TIP OPENING DISPLACEMENT}

\subsection{Description of the softwarefor numerical computations (FRANC3D)}

The state of stress and crack tip opening displacement (strain) in the examined specimens was analysed with boundary element method with the FRANC3D software (www.cfg.cornell.edu/software/software.htm). Geometric model of the specimen was performed using the OSM software application. The work in the OSM application began with modeling specimens by introducing coordinates of points forming a flat figure with a notch. The next step was to transform the flat outline of the specimen into 3D object. Then, the work in the FRANC3D software was started with introduction of operating range (linear-elastic, elastic-plastic) and material data. After entering the above data, the required specimens surfaces needed to be confirmed. For the presented example of numerical computations, the specimens is fixed by one end (taking away the numbers of degrees of freedom of nodes) (Fig. 3). The next step is to determine the method and load value of the specimens. The specimens was subjected under torsion (Fig. 3a) and bending with torsion (Fig. $3 b$ ) in accordance with the directions of the $x, y$ and $z$ axes.

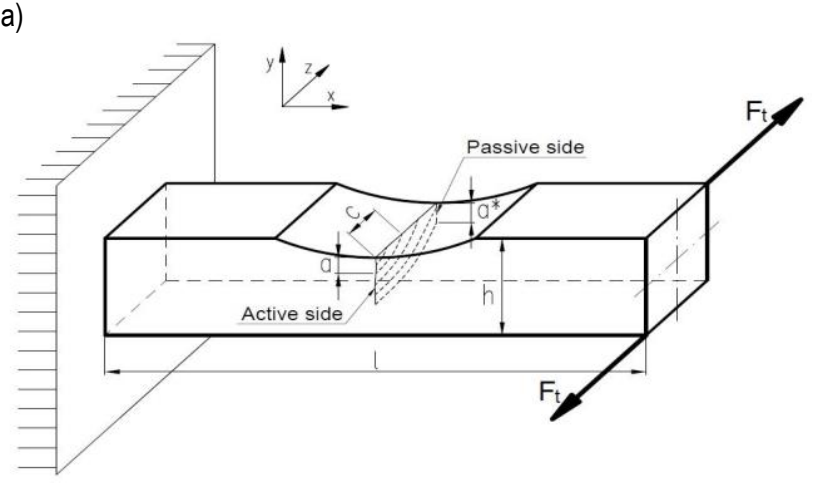

b)

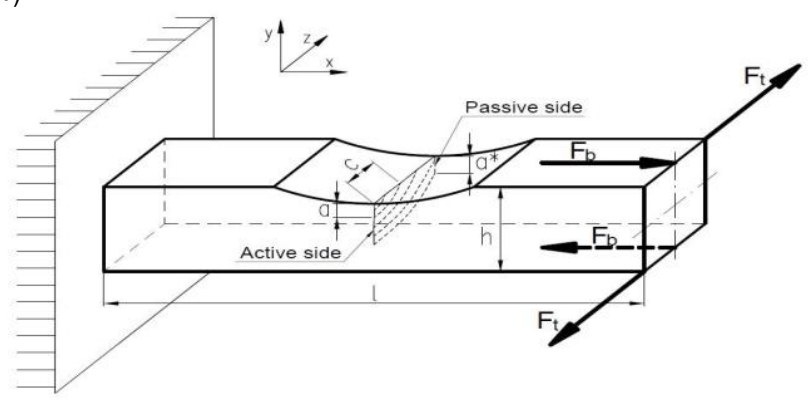

Fig. 3. The geometry of the specimen model with selected method of support and load for: a) torsion, b) bending with torsion

Bearing defined restrain and load, the boundary element mesh formation can be started. The size and shape of boundary elements depends on the division of section closing a given area (Faszynka and Rozumek, 2014). Fig. 4 shows networks of boundary elements for spatial model, consisting of 1209 triangular elements. 


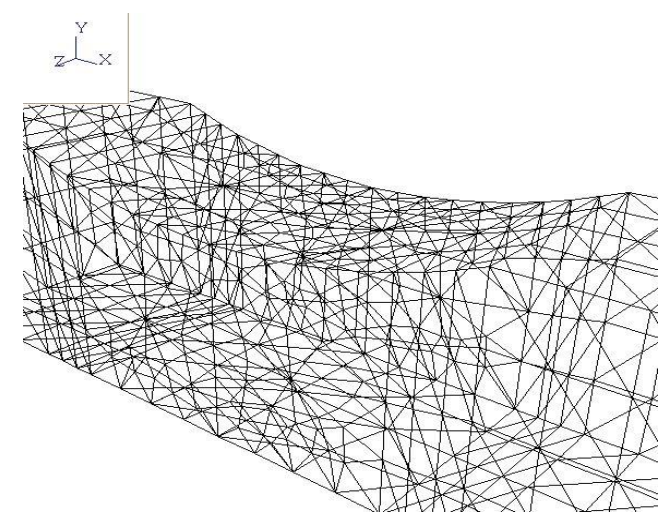

Fig. 4. Division into boundary elements of a specimen model around the bottom of the notch

First numerical computations of the state of stress without crack were performed on such a model of specimen. Furthermore, the next step of computations is the numerical analysis of stress and CTOD being performed around the crack tip opening displacement. In the calculation model, torsion crack were initiated in the form of the arc at the bottom of the notch with initial length of $0.1 \mathrm{~mm}$ on a side surface, and $0.1 \mathrm{~mm}$ on the upper surface. At the time of bending with torsion, the crack was initiated in the form of the arc of $0.1 \mathrm{~mm}$ length on the side surface, and of 0.3 $\mathrm{mm}$ on the upper surface. Introduced points were connected with curve in such a way that they anabled forming an edge of the crack. At the first steps of the crack growth, the FRANC3D software will form a surface of quarter-elliptic edge crack in the bottom of the notch, as shown in Fig. 5. Then, the crack goes across the specimen (various length of the crack at front and edge of the specimen), as shown in Fig. 6. a)

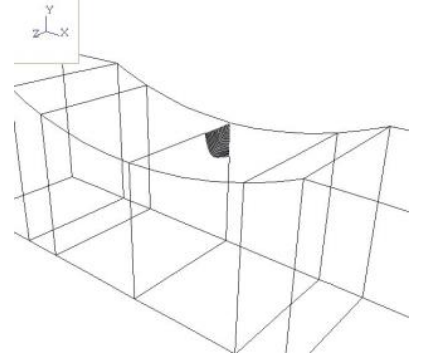

b)

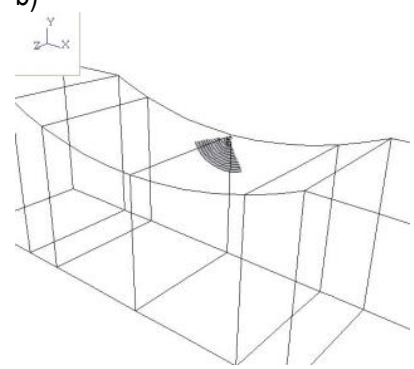

Fig. 5. Plane of quarter-elliptic crack at the edge of the notch: a) torsion, b) bending with torsion a)

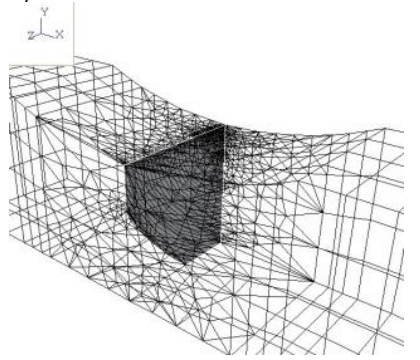

b)

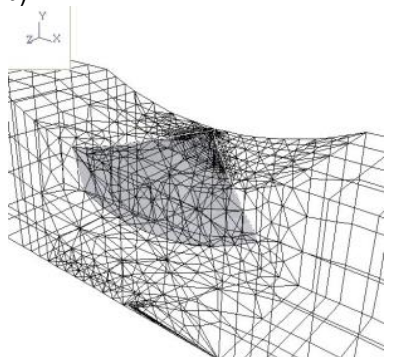

Fig. 6. Plane of through crack with division into boundary elements under: a) torsion, b) bending with torsion

The obtained plane of cracks should be divided into boundary elements. The method of division and the way in which the boundary element mesh is made at the place of crack initiation are the same as at the time, when the mesh was generated for the whole model. The next step is to perform numerical computations. For further recalculations on the crack growth, numerical values of crack growth and the total length of the crack were introduced. After the crack growth is being accepted, the program automatically enlarges the crack by a predetermined value (the program itself will set the path of crack growth according to the given load). In order to perform numerical analysis of crack growth, new planes should be further divided into smaller surface and a mesh of boundary elements should be developed. The process of distribution of new plane into smaller surfaces should be repeated as long as the desired length of the crack will be obtained or as the complete destruction of the test specimen will be reached (Faszynka and Rozumek, 2014).

\subsection{The results of numerical computations}

The results of numerical computations were presented in the form of maps of stress and crack tip opening displacement (CTOD) for spatial model of the specimen. Fig. 7 shows a specimen model without crack.

a)

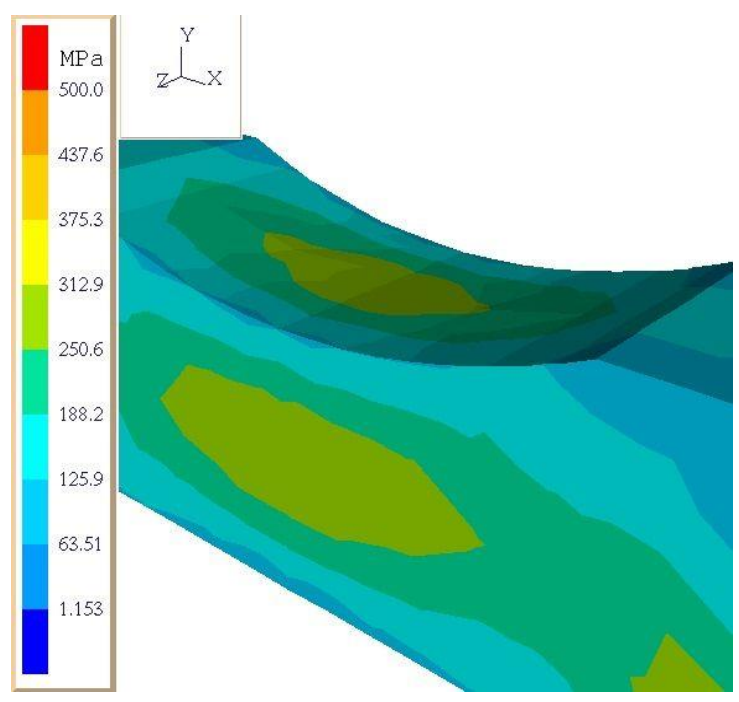

b)

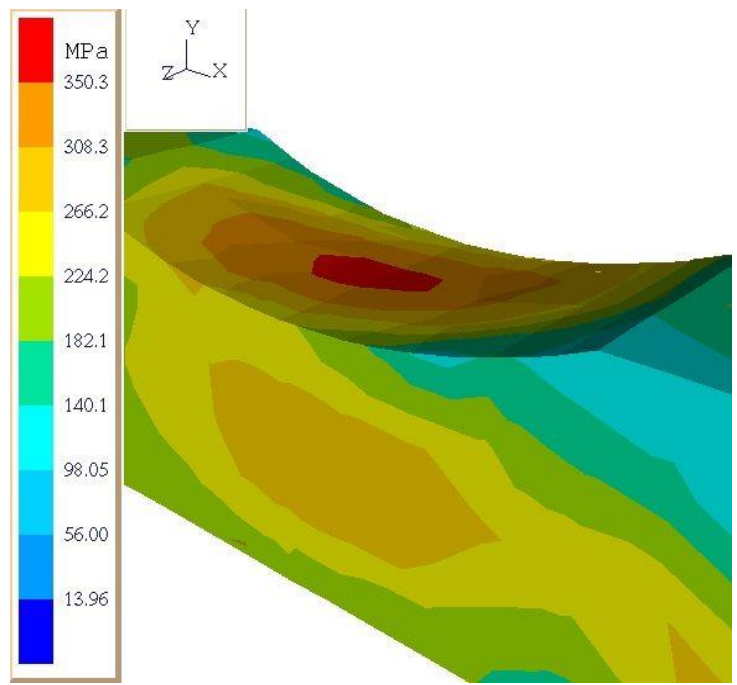

Fig. 7. Distribution of stresses in the specimen model (according to Huber-Mises) under: a) torsion, b) bending with torsion 
Figs. $8 \div 11$ present a model of the specimen with quarterelliptic edge crack. While in Figs. $12 \div 15$ a model of the specimen with a through the thickness crack. Computations were made for a specimen model under torsion (Fig. 3a) and proportional bending with torsion (Fig. 3b). The exemplary results of the numerical computations for the specimen model without crack are shown in Fig. 7a (torsion) and in Fig. 7b (bending with torsion) as stress maps. Numerical computations on the crack growth were performed by employing the incremental method for crack lengths, corresponding to the cracks obtained during experimental tests (Faszynka et al., 2015). A non-uniform fatigue cracks growth on both lateral surfaces of specimens (active side and passive side) was observed during experimental tests under torsion and bending with torsion. The development of fatigue cracks in the specimens was performed in two stages: at first, the quarterelliptic edge cracks were observed and then they were transforming into the through the thickness crack. Fig. 8 shows the stress distribution in the model of the specimen (according to HuberMises Hypothesis) for load $M_{T}=15.84 \mathrm{~N} \cdot \mathrm{m}(R=-1)$ under torsion, with a quarter-elliptic edge crack and the length of $a=2.00 \mathrm{~mm}$ (lateral side of the specimen) and $c=2.20 \mathrm{~mm}$ depth (at the notch root).

a)

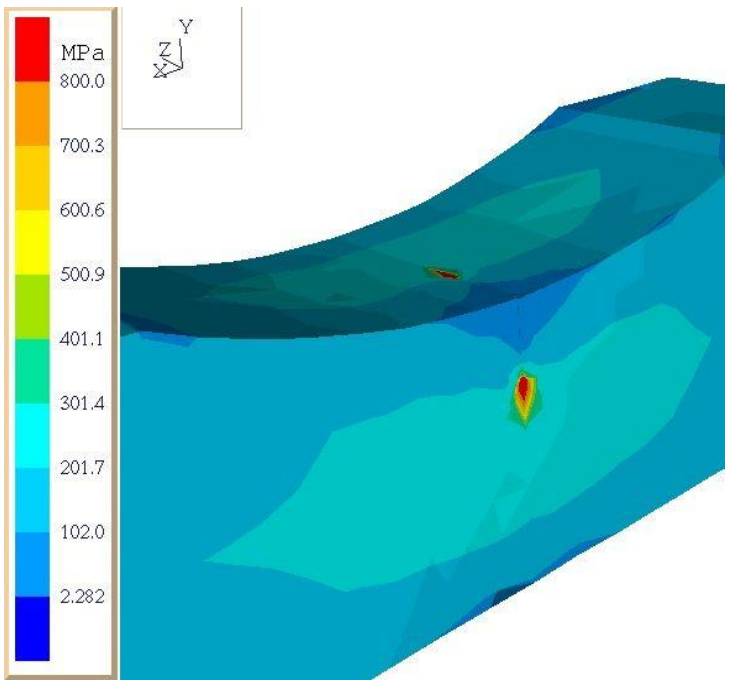

b)

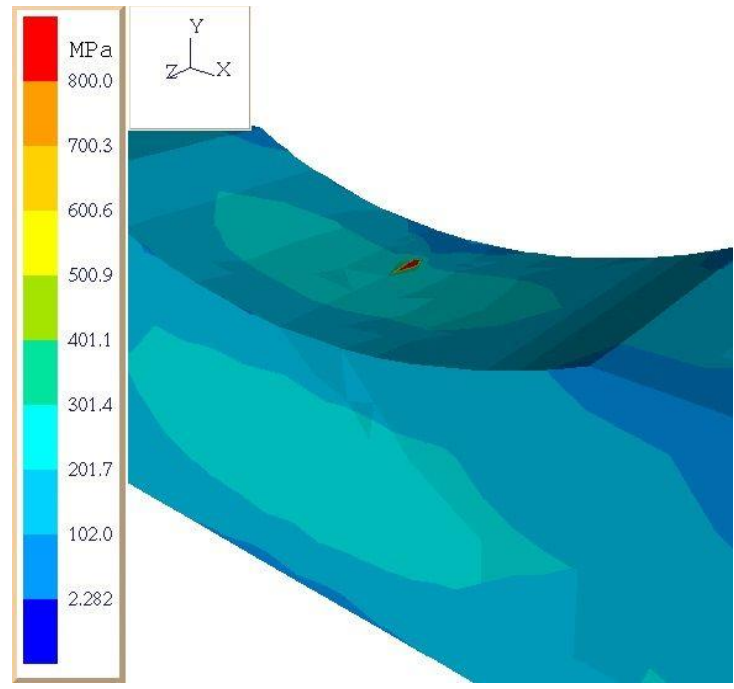

Fig. 8. Distribution of stresses in the specimen model (according to Huber-Mises) for quarter-elliptic edge crack length of $a=2.00 \mathrm{~mm}$ and depth of $c=2.20 \mathrm{~mm}$ under torsion: a) active side,

b) passive side

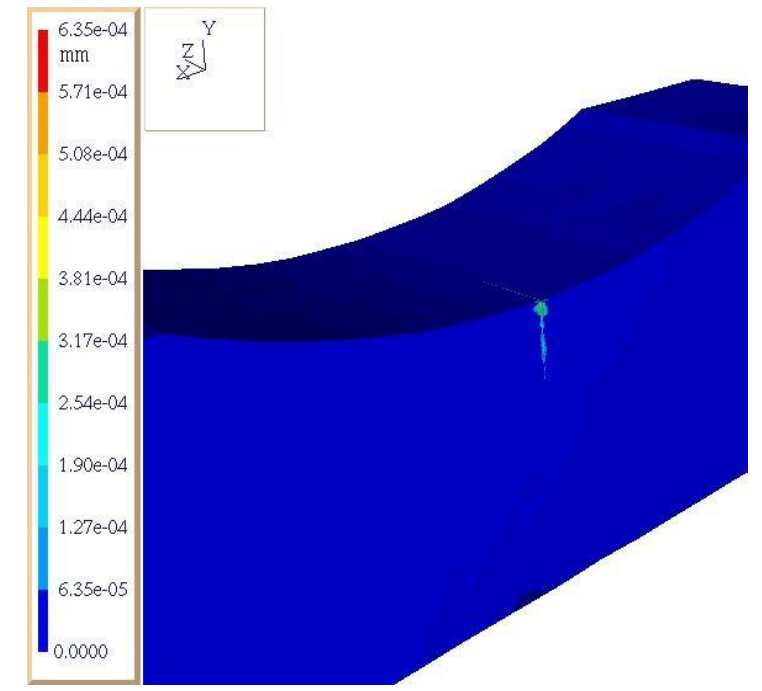

Fig. 9. Crack tip opening displacement maps for a quarter-elliptic edge crack length of $a=2.00 \mathrm{~mm}$ and depth of $c=2.20 \mathrm{~mm}$ (active side) under torsion

a)

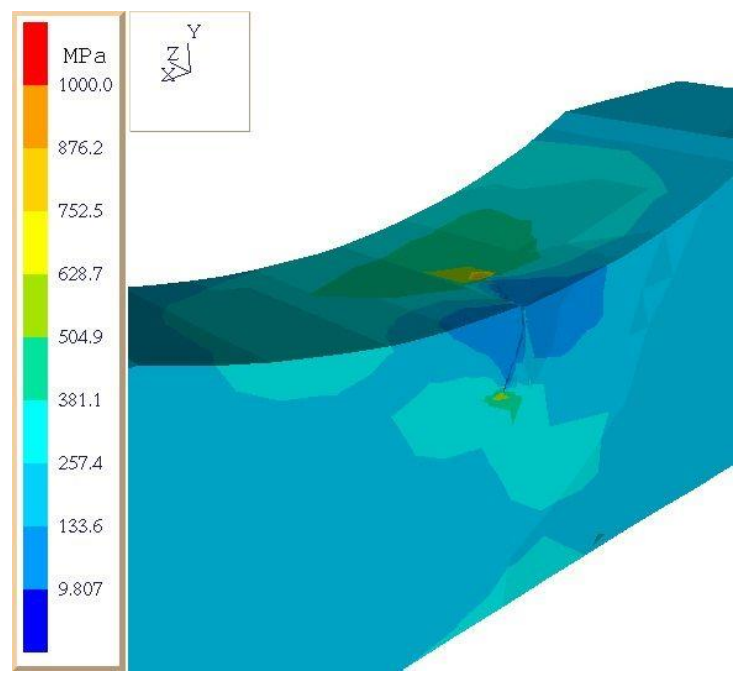

b)

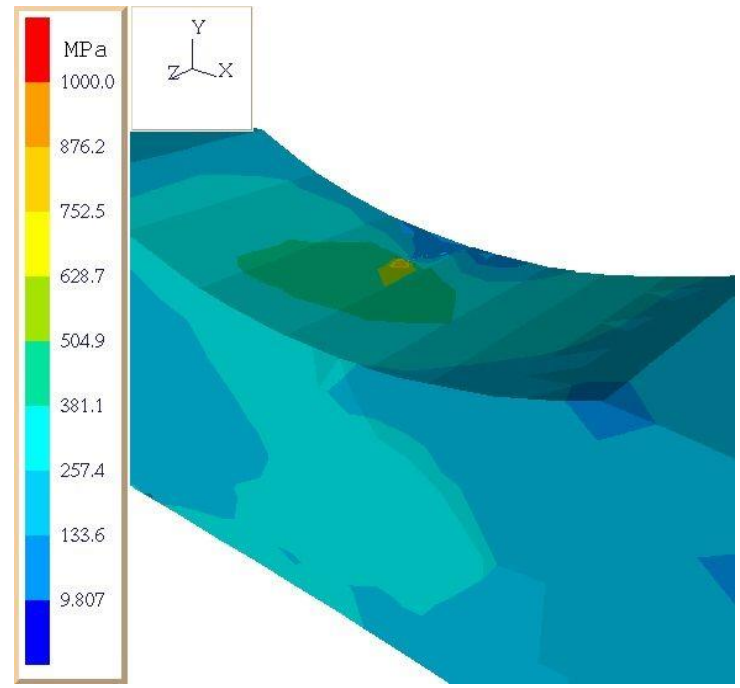

Fig. 10. Distribution of stresses in the specimen model (according to Huber-Mises) for quarter-elliptic edge crack length of $a=2.50 \mathrm{~mm}$ and depth of $c=2.80 \mathrm{~mm}$ under bending with torsion: a) active side, b) passive side 
Fig. 9 presents the crack tip opening displacement (CTOD) at load $\mathrm{M}_{\mathrm{T}}=15.84 \mathrm{~N} \cdot \mathrm{m}(\mathrm{R}=-1)$ under torsion, with a quarterelliptic edge crack with the length of $\mathrm{a}=2.00 \mathrm{~mm}$ (lateral side of the specimen) and $\mathrm{c}=2.20 \mathrm{~mm}$ depth (at the notch root).

Fig. 10 indicates distribution of stresses in the specimen model (according to Huber-Mises) for the load $M_{B T}=15.84 \mathrm{~N} \cdot \mathrm{m}$ $(R=-1)$ under bending with torsion, with a quarter-elliptic edge crack length of $a=2.50 \mathrm{~mm}$ and depth of $c=2.80 \mathrm{~mm}$. Fig. 8 and 10 ensure that the highest value of stress are at the notch root than on the lateral side of the specimen (h peak values, Fig. 3). By comparing the Figs. 8 and 10 it can be noted that greater stress values in crack tip opening occur for bending with torsion than for torsion. Fig. 11 presents CTOD maps for the load $M_{B T}=$ $15.84 \mathrm{~N} \cdot \mathrm{m}(R=-1)$ under bending with torsion, for a quarterelliptic edge crack length of $a=2.50 \mathrm{~mm}$ and depth of $c=2.80$ $\mathrm{mm}$. During comparison of Figs. 9 and 11, the greater CTOD values for bending with torsion rather than for torsion were observed.

a)

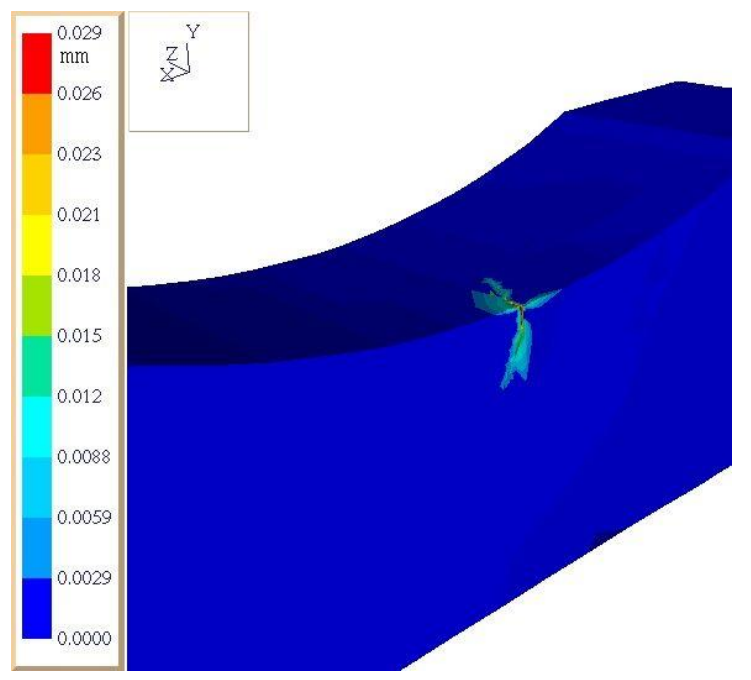

b)

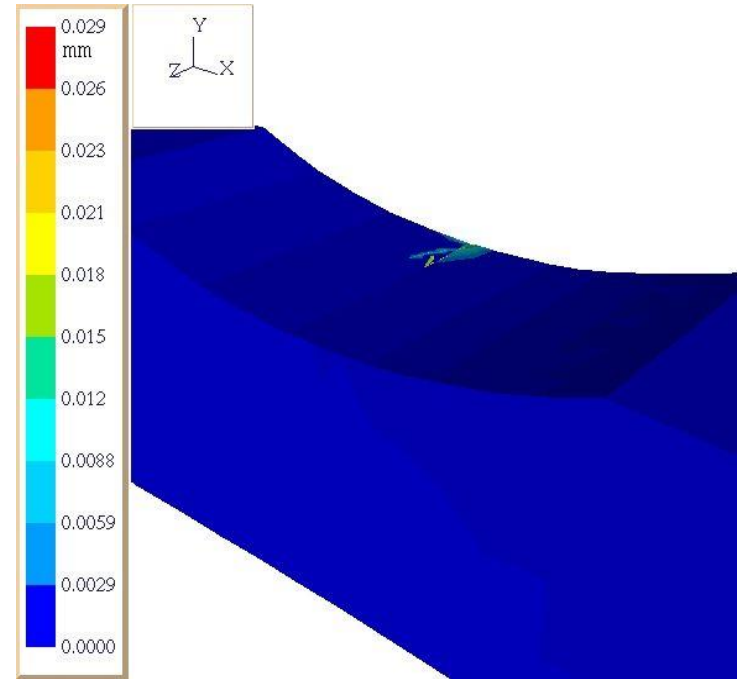

Fig. 11. Crack tip opening displacement maps for a quarter-elliptic edge crack length of $a=2.50 \mathrm{~mm}$ and depth of $c=2.80 \mathrm{~mm}$ under bending with torsion: a) active side, b) passive side

Figs. $12 \div 15$ represent exemplary results of numerical computations for the specimen model with the through the thickness crack. Measurement of the crack length was carried out on both sides of specimens. On the active side (Fig. 12a) the cracks were a greater than on the passive side (Fig. 12b). Larger crack length on the active side causes reduction of cross-section of the specimen without crack, which leads to stress increase. For calculations purposes, the greater lengths of cracks are assumed simple because they obtain the greatest stress values and have major impact on the specimen failure. On the active side, the crack lengths were marked with the letter "a", and on the passive side with the letter "a*". Fig. 12 indicate distribution of stresses in the specimen model (according to Huber-Mises) for the load $M_{T}=15.84 \mathrm{~N} \cdot \mathrm{m}(R=-1)$ under torsion, with the through the thickness crack length of $\mathrm{a}=8.00 \mathrm{~mm}$ (active side of the specimen) and the length of $a^{*}=2.50 \mathrm{~mm}$ (passive side of the specimen).

a)

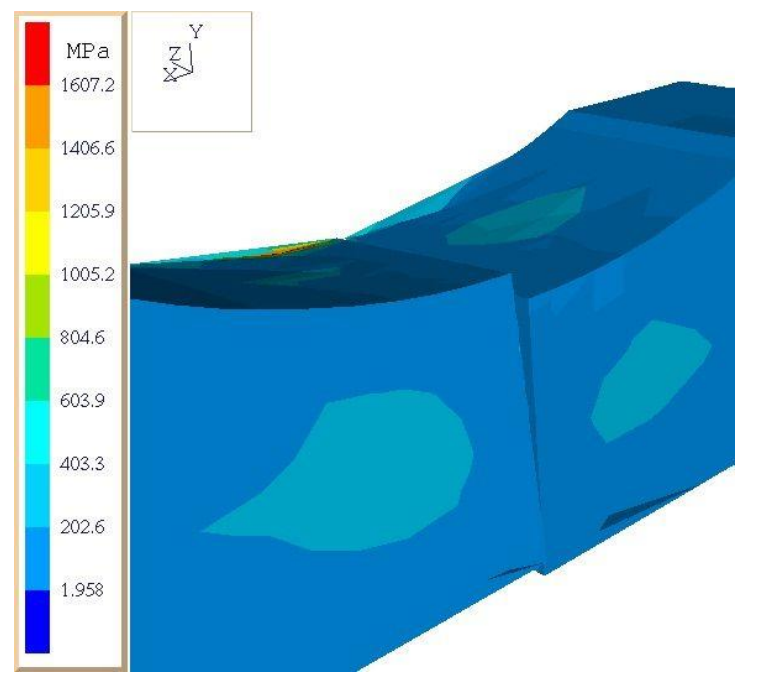

b)

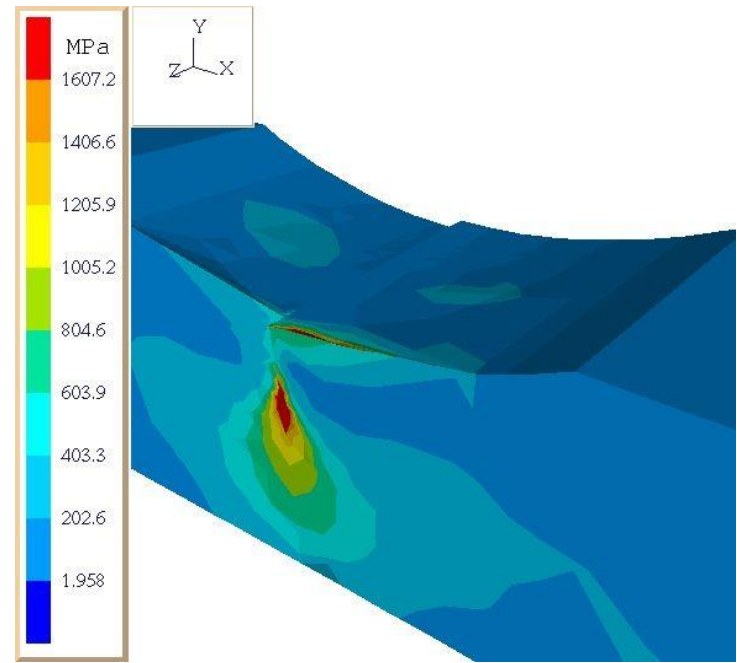

Fig. 12. Distribution of stresses in the specimen model (according to Huber-Mises) for through crack length of $a=8.00 \mathrm{~mm}$ and the length of $\mathrm{a}^{*}=2.50 \mathrm{~mm}$ under torsion: a) active side, b) passive side

Fig. 13 presents crack tip opening displacement maps for the load $M_{T}=15.84 \mathrm{~N} \cdot \mathrm{m}(R=-1)$ under torsion, with through the thickness crack length of $a=8.00 \mathrm{~mm}$ and the length of $a^{*}=$ $2.50 \mathrm{~mm}$.

Fig. 14 shows distribution of stresses in the specimen model (according to Huber-Mises) for the load MBT $=15.84 \mathrm{~N} \cdot \mathrm{m}(R=-1)$ under bending with torsion, with through the thickness crack length of $a=6.10 \mathrm{~mm}$ and the length of $a^{*}=2.60 \mathrm{~mm}$. Comparing 
Figs. 12 and 14, the various lengths of cracks at both sides of the specimen can be distinguished under torsion and under bending with torsion. Despite the $\mathrm{M}_{\mathrm{B}}$ to $M_{T}$ ratio being applied during the research tests, differences in length of crack growth on the active and passive side of the specimen could be always observed. By comparing Figs. 12 and 14 could be easily seen that greater stress in crack tip opening displacement are observed for torsion rather than for bending with torsion. Comparison of Figs. 8 and 12 with Figs. 10 and 14 shows that longer cracks indicate higher stress values.

Fig. 15 presents crack tip opening displacement maps for the load $M_{B T}=15.84 \mathrm{~N} \cdot \mathrm{m}(\mathrm{R}=-1)$ under bending with torsion, for through the thickness crack length of $a=6.10 \mathrm{~mm}$ and the length of $a^{*}=2.60 \mathrm{~mm}$. Crack tip opening displacement for the quarterelliptic edge cracks and the through the thickness cracks is greater under bending with torsion than under torsion.

a)

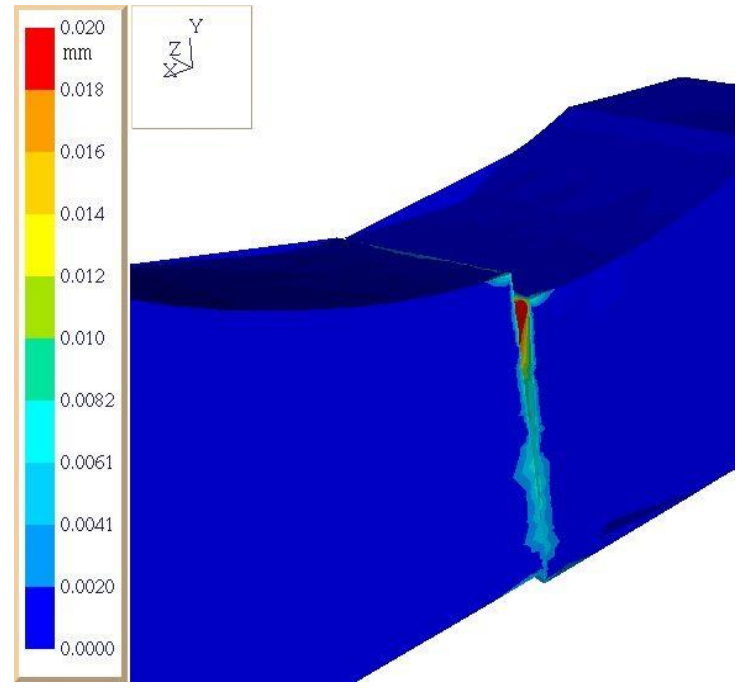

b)

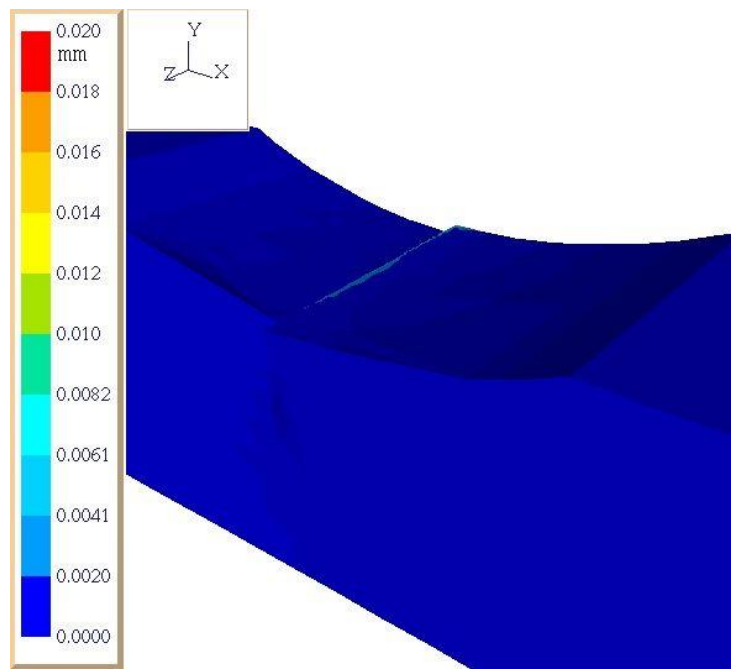

Fig. 13. Crack tip opening displacement maps for through the thickness crack length of $a=8.00 \mathrm{~mm}$ and the length of $a^{*}=2.50 \mathrm{~mm}$ under torsion: a) active side, b) passive side a)

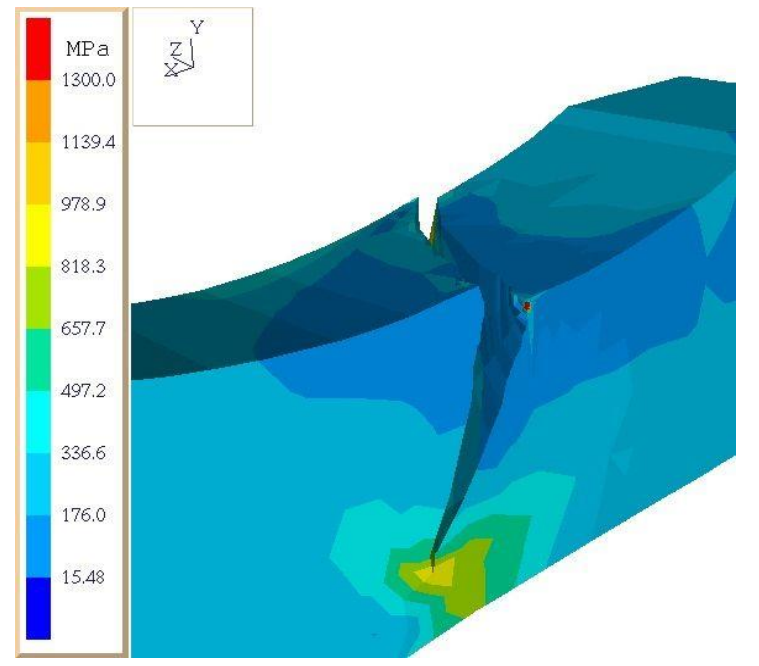

b)

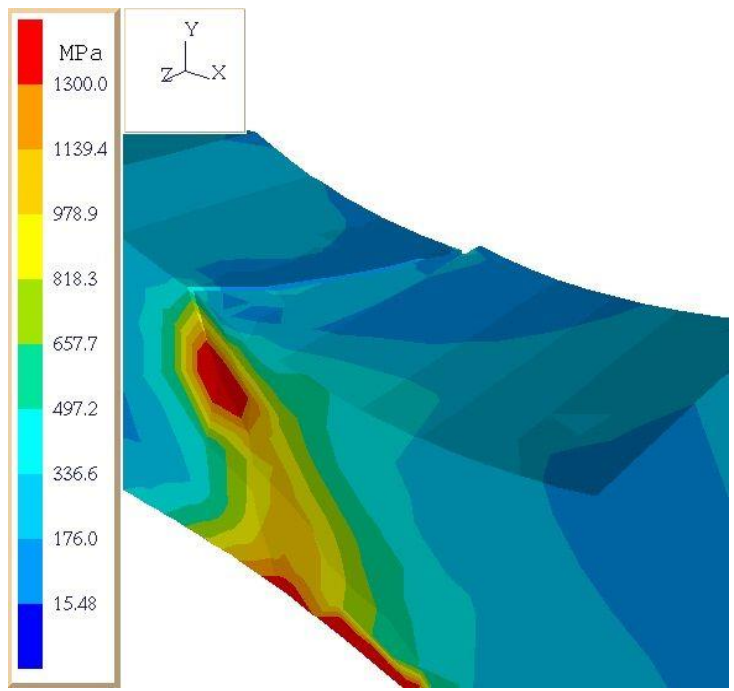

Fig. 14. Distribution of stresses in the specimen model (according to Huber-Mises) for through the thickness crack length of $a=6.10$ $\mathrm{mm}$ and the length of $\mathrm{a}^{*}=2.60 \mathrm{~mm}$ under bending with torsion: a) active side, b) passive side

During numerical computations, the observed track of crack growth (the quarter-elliptic edge and the through the thickness crack) under torsion and under bending with torsion was at the same direction as during experimental tests (Zappalorto et al., 2011; Brighenti et al., 2012). To illustrate it, the nominal stress values obtained by using the BEM method (numerical calculations) were compared to these values received from analytical calculations (Susmel and Taylor, 2007). The stress values for the active length quarter-elliptic edge cracks $a=2.00 \mathrm{~mm}$ (for torsion) and $a=2.50 \mathrm{~mm}$ (for bending with torsion) were $\tau_{n}=175.7 \mathrm{MPa}$ (for torsion) when using BEM method, and $\tau_{n}=162.1 \mathrm{MPa}$ when applying the analytical method. The stress values for bending with torsion were $\sigma_{n}=242.7 \mathrm{MPa}$ when using BEM method, and $\sigma_{n}=$ 266.6 MPa when applying the analytical method. By comparing both methods of computation for the presented example, it was marked that the relative error does not exceed $10 \%$. Superiority of the BEM method over the analytical method is derived from the ability to obtain stress distribution near the crack tip opening displacement. 
a)

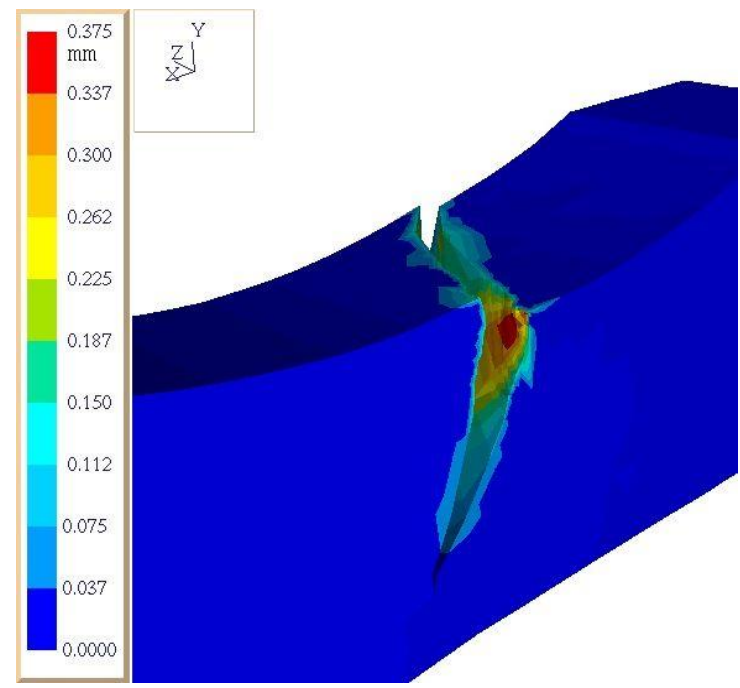

b)

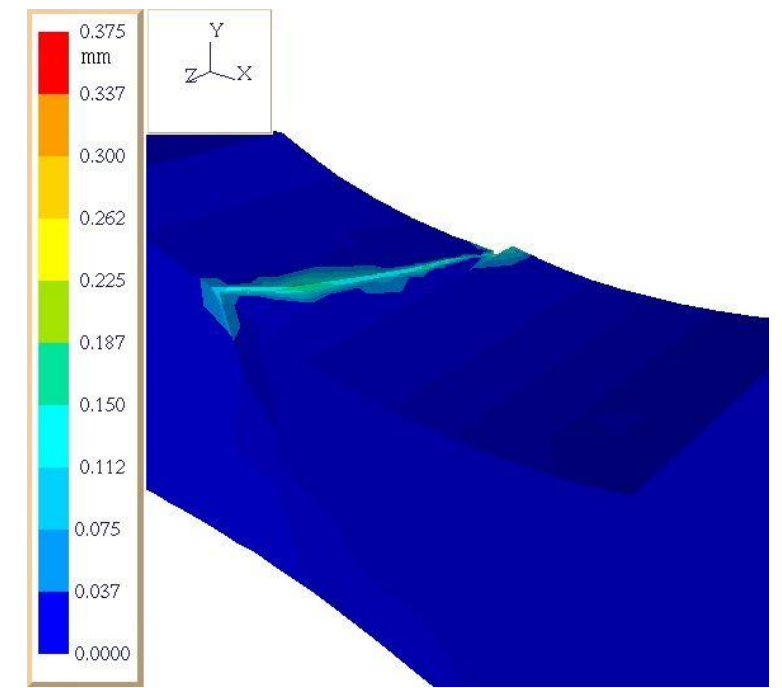

Fig. 15. Crack tip opening displacement maps for through crack length of $a=6.10 \mathrm{~mm}$ and the length of $a^{*}=2.60 \mathrm{~mm}$ under bending with torsion: a) active side, b) passive side

\section{CONCLUSIONS}

Numerical computations for cracks growth allow for the following conclusions:

1. Atquarter-elliptic edge cracks, the values of stresses are higher of approx. $9.5 \%$ for bending with torsion than for torsion.

2. At thethrough the thickness cracks, the values of stresses are higher of approx. $23.6 \%$ for torsion than for bending with torsion.

3. The FRANC3D software is one of the few programs that can be employed for numerical computations of cracks growth.

\section{REFERENCES}

1. Becker A.A. (1992), The boundary element method in engineering, McGraw - Hill International, New York.

2. Brighenti R., Carpinteri A., Vantadori S. (2012), Fatigue life assessment under a comlpex multiaxial load history: an approach based on damage mechanics, Fatigue \& Fracture of Engineering Materials \& Structures, Vol. 35, 141-153.

3. Derpeński Ł., Seweryn A. (2007), Numerical analysis of fracture for specimens with notches made of elasto-plastic material, Acta Mechanica et Automatica, Vol. 1 (1), 27-30 (in Polish).

4. Döring R., Hoffmeyer J., Seeger T., Vormwald M. (2006), Short fatigue crack growth nonproportional multiaxial elastic-plastic strains, International Journal of Fatigue, Vol. 28 (9), 972-982.

5. Duchaczek A., Mańko Z. (2012), Assessment of direct method of calculating stress intensity factor, Journal of Science of the gen. Tadeusz Kosciuszko Military Academy of Land Forces, No. 3 (165), 336-346 (in Polish).

6. Faszynka S., Rozumek D. (2014), Application of the FRANC3D software for crack growth calculations, Mechanik, No. 11, 932-934 (in Polish).

7. Faszynka S., Rozumek D., Lewandowski J. (2015), Crack growth path in specimens with rectangular section under bending with torsion, Solid State Phenomena, Vol. 224, 133-138.

8. Kleiber M. (1995), Computational methods in mechanics of solids, Warsaw, PWN (in Polish).

9. Rozumek D., Hepner M., Faszynka S. (2015),Fatigue tests of PA6 and PA7 alloys subjected to bending without and after precipitation hardening, Mechanik, No. 3, 246-249 (in Polish).

10. Rozumek D., Macha E. (2006), Elastic-plastic fatigue crack growth in 18G2A steel under proportional bending with torsion loading,Fatigue \& Fracture of Engineering Materials \& Structures, Vol. 29 (2), 135-145.

11. Rozumek D., Macha E.(2009), J-integral in the description of fatigue crack growth rate induced by different ratios of torsion to bending loading in AlCu4Mg1, Mat.-wiss. u. Werkstofftech., Vol. 40 (10), 743-749.

12. Rusiński E. (2002), Design principles supporting structures of motor vehicles, Oficyna Wydawnicza PolitechnikiWrocławskiej, Wrocław (in Polish).

13. Seweryn A., (2002),Modeling of singular stress fields using finite element method,Int. Journal of Solids and Structures, Vol. 39 (18), 4787-4804.

14. Susmel L., Taylor D. (2007), Non-propagating cracks and high-cycle fatigue failures in sharply notched specimens under in-phase Mode I and II loading, Engineering Failure Analysis, Vol. 14, 861-876.

15. Szusta J., Seweryn A. (2010), Fatigue damage accumulation modelling in the range of complex low-cycle loadings - The strain appoach and its experimental verification on the basis of EN AW2007 aluminium alloy, International Journal of Fatigue, Vol. 33 (2), 255-264.

16. Thum A., Petersen C., Swenson O. (1960), Deformation, stress and notch effect, VDI, Duesseldorf (in German).

17. Zappalorto M., Berto F., Lazzarin P. (2011), Practical expressions for the notch stress concentration factors of round bars under torsion, International Journal of Fatigue, Vol. 33 (3), 382-395.

18. Zienkiewicz O. C., Taylor R. L. (2000), The finite element method, Buttenworth Heinemann, Vol. 1-3, Oxford.

19. www.cfg.cornell.edu/software/software.htm. 